\title{
MicroRNAs: a new ray of hope for diabetes mellitus
}

\author{
Munish Kumar ${ }^{1 \bowtie}$, Sayantan Nath ${ }^{1}$, Himanshu K Prasad ${ }^{2}$, G D Sharma ${ }^{2}$, Yong Li ${ }^{3 凶}$ \\ ${ }^{1}$ Department of Biotechnology, Assam University, Silchar 788011, India \\ 2 Department of Life Science and Bioinformatics, Assam University, Silchar 788011, India \\ ${ }^{3}$ Department of Biochemistry and Molecular Biology, University of Louisville, KY 40292, USA \\ $\triangle$ Correspondence: munishkp@gmail.com (M. Kumar); yong.li@louisville.edu (Y. Li) \\ Received June 4, 2012 Accepted July 1, 2012
}

\begin{abstract}
Diabetes mellitus has become one of the most common chronic diseases, thereby posing a major challenge to global health. Characterized by high levels of blood glucose (hyperglycemia), diabetes usually results from a loss of insulin-producing $\beta$-cells in the pancreas, leading to a deficiency of insulin (type 1 diabetes), or loss of insulin sensitivity (type 2 diabetes). Both types of diabetes have serious secondary complications, such as microvascular abnormalities, cardiovascular dysfunction, and kidney failure. Various complex factors, such as genetic and environmental factors, are associated with the pathophysiology of diabetes. Over the past two decades, the role of small, single-stranded noncoding microRNAs in various metabolic disorders, especially diabetes mellitus and its complications, has gained widespread attention in the scientific community. Discovered first as an endogenous regulator of development in the nematode Caenorhabditis elegans, these small RNAs post-transcriptionally suppress mRNA target expression. In this review, we discuss the potential roles of different microRNAs in diabetes and diabetes-related complications.
\end{abstract}

KEYWORDS diabetes, diabetic complications, dicer, glucose, insulin, microRNA, pancreas

\section{INTRODUCTION}

Diabetes mellitus is a chronic disease caused by defects in the way the body makes or responds to insulin, resulting in high levels of glucose in the blood (hyperglycemia). There are two major types of diabetes: type 1 (T1D), resulting from autoimmune destruction of insulin-producing $\beta$-cells in the pancreas, and type 2 (T2D), resulting from insulin resistance (Tang et al., 2008) and accounting for over $90 \%$ of all diabetes. Insulin resistance is a pathological condition in adipose tissue, liver, and skeletal muscle where insulin becomes less effective in lowering glucose levels. A third form of diabetes mellitus is gestational diabetes, which develops in pregnant woman who have never before had diabetes. Diabetes is frequently associated with microvascular (retinal, renal, or possibly neuropathic), macrovascular (coronary or peripheral vascular), or neuropathic (autonomic or peripheral) complications.

With rapid urbanization, industrialization, and globalization, widespread socio-economic prosperity has been achieved, but lack of physical activity due to a sedentary lifestyle has made humans more prone to obesity and diabetes. The World Health Organization (WHO) reported that, as of 2000 , there were 171 million cases of diabetes worldwide and this number will rise to 366 million, or $4 \%$ of the population, in 2030 (Shaw et al., 2010). Thus, diabetes mellitus is becoming a major public health concern and a huge economic burden in both developed and developing nations. There is therefore a critical need for new therapeutic strategies to better control glucose homeostasis.

With the completion of the human genome sequence, it was found that the vast majority of the genome does not actually encode proteins, but instead consist of noncoding functional elements and non-functional sequences that have been referred to as "junk DNA". In recent years, the discovery of a family of small ( 22 nucleotide) single-stranded, noncoding, endogenous RNAs, called microRNAs (miRNAs), has been a focus of attention for researchers. The first miRNA, lin-4, was discovered by Ambros and his co-workers in 1993 as an endogenous regulator of genes that control developmental timing in the nematode Caenorhabditiselegans ( $C$. 
elegans) by down-regulating protein levels of its target gene lin-14 (Lee et al., 1993). Subsequently, numerous miRNAs have been reported to be present in various organisms, including human. miRNAs function as translational repressors by inhibiting the expression of specific genes through base pairing between the miRNA "seed region" and the 3' untranslated regions (UTRs) of the target mRNAs. One miRNA may control multiple genes, and one gene may be controlled by multiple miRNAs (Carè et al., 2007; Pandey et al., 2009). Acting both upstream and downstream of key cellular transcription factors, miRNAs can exert multiple effects and play important roles in, for example, development, stress responses, cardiovascular diseases, angiogenesis, oncogenesis, and diabetes (Mishra et al., 2009; Zampetaki et al., 2010; Kumar et al., 2011). There are $>1000$ miRNAs encoded by the human genome (Bartel, 2004; Berezikov et al., 2005), which are collectively annotated and indexed in the miRNA registry (http://microrna.sanger.ac.uk).

\section{BIOGENESIS OF MIRNAS}

The biogenesis of miRNAs starts in the nucleus, where several-kilobase or longer primary miRNA sequences (pri-miRNAs) are transcribed from the genome and then capped, spliced and polyadenylated (Cai et al., 2004). While RNA polymerase II transcribes most miRNAs, those associated with short, interspersed nuclear elements or derived from viruses are transcribed by RNA polymerase III (Dieci et al., 2007). Pri-miRNAs are processed by Microprocessor, which is a complex consisting of Drosha, a nuclear RNase III enzyme, and its essential cofactor protein (encoded in human by DiGeorge syndrome critical region gene 8 [DGCR8] and in Drosophila and C. elegansby Pasha) (Muhonen and Holthofer, 2009), into 70-nucleotide (nt)-long hairpin-shaped premature miRNAs (pre-miRNAs). They are exported out of the nucleus to the cytoplasm by a RanGTP/exportin-5-dependent mechanism (Muhonen and Holthofer, 2009). Dicer, a cytoplasmic RNase III enzyme, associates with the transactivation-responsive RNA-binding protein (TRBP, also known as TARBP2) and cleaves pre-miRNAs to release a short, 22-base-pair (bp)-long RNA duplex. Having lower thermodynamic stability at its 5 '-end, the miRNA strand is selected by the miRNA-induced silencing complex (miRISC) before incorporation into the complex. The miRISC acts as the effector of the miRNA pathway, interacting with messenger RNA (mRNA) to suppress its translation or cause its degradation (Fig. 1).

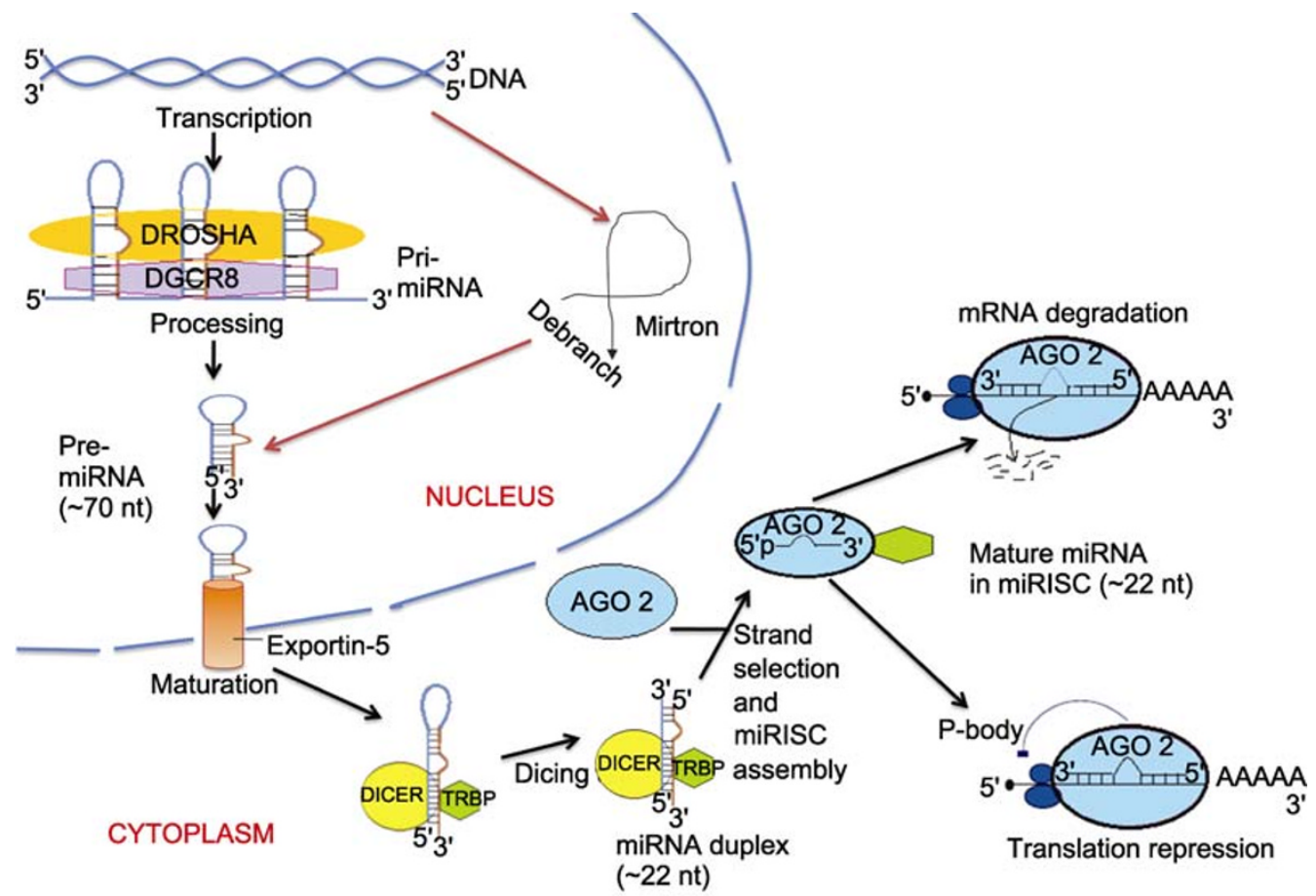

Figure 1. Schematic diagram of the biogenesis of miRNA and its mechanism of action. In the nucleus the primary miRNAs (pri-miRNAs) are transcribed from the genome by RNA polymerase II which are then processed by Microprocessor (Drosha and DGCR8) into precursor miRNAs (pre-miRNAs). These pre-miRNAs are then exported into the cytoplasm by a Ran-GTP dependent nuclear transport receptor, exportin 5 where they are further processed into $\sim 22$ nucleotide long miRNA duplex by Dicer and its interacting partner, TRBP (TAR RNA Binding Protein). One strand of this miRNA duplex along with Dicer, TRBP and a member of the Argonaute protein fadown-regmily (AGO2) assembles into the miRNA Induced Silencing Complex (miRISC). Mature miRNAs then regulate gene expression by guiding the miRISC to their target complementary mRNA, causing mRNA degradation and repression of translation initiation. Mirtrons are produced from pri-miRNA-sized introns that form a looped intermediate called a lariat, which are then debranched and refolded into pre-miRNAs that enter the canonical biogenesis pathway. 
In another biogenesis pathway identified in 2007, miRNAs can be derived from introns of sufficient size to form pre-miRNAs(Okamura et al., 2007; Ruby et al., 2007). Maturation of these miRNAs (termed mirtrons) bypasses the Drosha processing step. The spliceosome splices mirtrons out of their host gene transcript to form looped (lariat) intermediates, which are then debranched and refolded into the usual stem loop pre-miRNA structure that accesses the canonical biogenesis pathway (Fig. 1).

\section{THE INSULIN PATHWAY}

Insulin secreted by $\beta$-cells of the pancreas functions to stimulate the uptake of nutrients (glucose, amino acids, and fatty acids) and their conversion into storage macromolecules (glycogen, protein, and lipids) in skeletal muscle, adipose tissue, and liver. The insulin receptor (IR) is composed of two extracellular $\alpha$ subunits and two transmembrane $\beta$ subunits linked together by disulphide bonds. Binding of insulin to the a subunit induces a conformational change, allowing autophosphorylation of several tyrosine residues in the $\beta$ subunit. IR activation leads to the phosphorylation of key tyrosine residues on insulin receptor substrate family (IRS). There are at least three IRS proteins in humans and mice, including IRS1 and IRS2, which are widely expressed, and IRS-4, which is limited to the thymus, brain, kidney, and $\beta$ cells (Uchida et al., 2000), while IRS3 is present only in mice and is largely restricted to adipose tissue, fulfilling a similar function as IRS1. Knockout of IRS1 produces small and insulin-resistant mice, whereas IRS2-deficient mice are infertile and develop diabetes, but are of normal size (White, 2002). There are two major branches of the insulin pathway (Fig. 2):

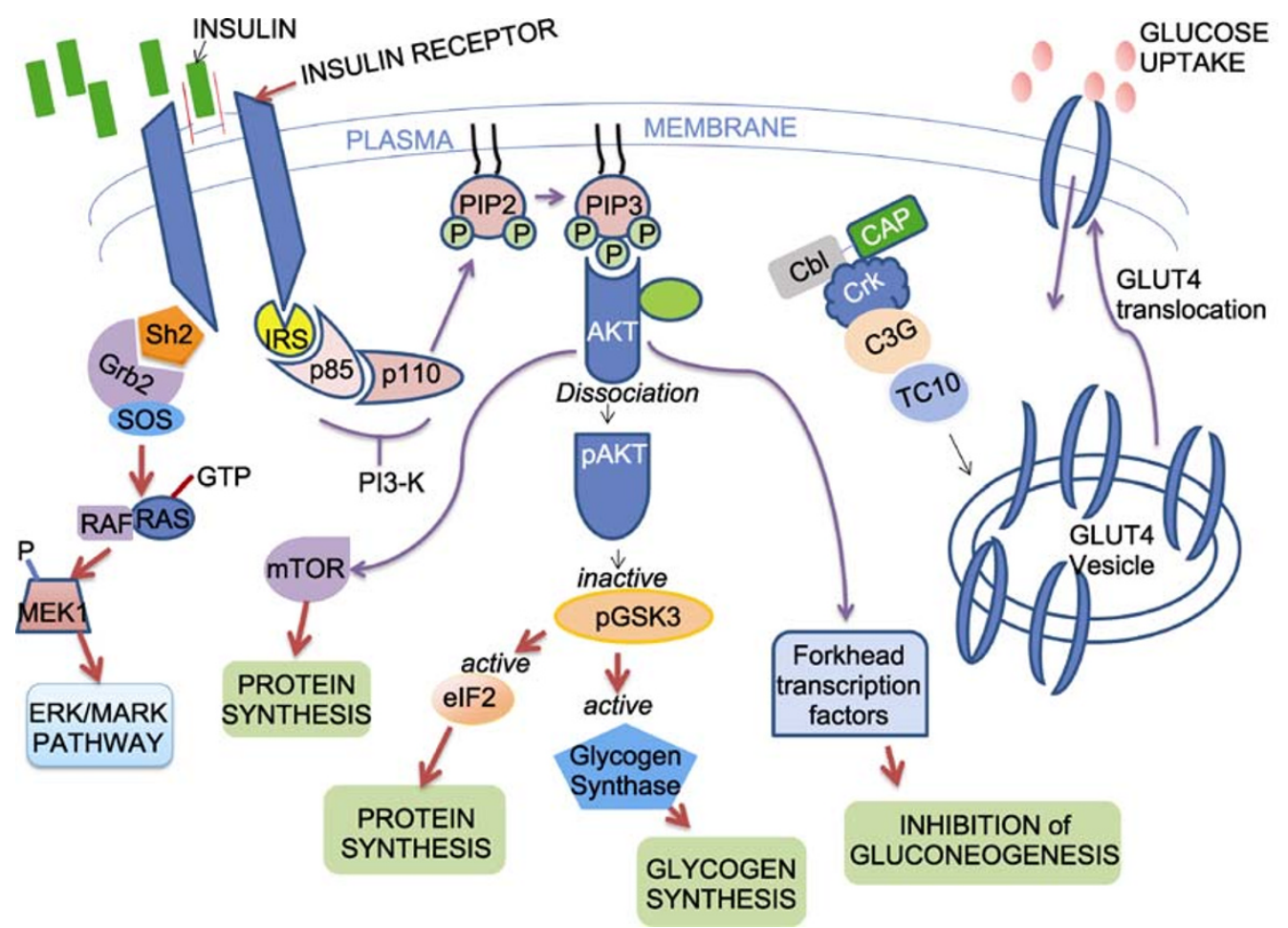

Figure 2. Schematic diagram of the insulin signaling pathway. Binding of insulin to the $\alpha$ subunit induces a conformational change, allowing autophosphorylation of a number of tyrosine residues in the $\beta$ subunit. In ERK branch of the pathway, growth factor binding protein 2 (Grb2) binds to the phosphotyrosine residues of the activated insulin receptor by its Src homology 2 (SH2) domain, which leads to the activation of downstream Ras, Raf, and the MEK1 kinase cascade, resulting in phosphorylation and activation of MAP kinase isoforms ERK1 and ERK2. In the Akt-signaling branch, the insulin receptor $\beta$ residues are recognized by phosphotyrosine-binding (PTB) domains of adaptor proteins, such as members of the insulin receptor substrate family (IRS), leading to the phosphorylation of key tyrosine residues on IRS proteins, some of which are recognized by the $\mathrm{SH} 2$ domain of the p85 regulatory subunit of PI 3-kinase (a lipid kinase). The catalytic subunit of PI 3-kinase, p110, then phosphorylates phosphatidylinositol $(4,5)$-bisphosphate (PIP2) leading to the formation of phosphatidylinositol $(3,4,5)$-trisphosphate (PIP3). Akt activation requires protein kinase 3'-phosphoinositide-dependent protein kinase-1 (PDK1), which leads to the phosphorylation of Akt. Once active, Akt enters the cytoplasm, where it leads to the phosphorylation and inactivation of glycogen synthase kinase 3 (GSK3), which activates glycogen synthase. Akt also directly activates mTOR and Forkhead transcription factors. PI3-kinase and Akt are known to play these important roles in GLUT4 translocation to the plasma membrane and, as a result, glucose enters the cell. Another way by which GLUT4 translocation takes place is through Casitas B-lineage lymphoma protein (Cbl) and its association with the adaptor protein CAP (Cbl-associated protein). 
MAP kinase (ERK) and AKT. The ERK branch is mediated by growth factor binding protein 2 (Grb2) and son of sevenless complex (SOS), which lead to the activation of downstream Ras, Raf, and the MEK1 kinase cascade, resulting in phosphorylation and activation of the MAP kinases ERK1 and ERK2. The AKT branch is mediated by IRS and the PI 3-kinase, causing PDK1 activation that leads to the phosphorylation of Akt. Once active, Akt enters the cytoplasm where it leads to the phosphorylation and inactivation of glycogen synthase kinase 3 (GSK3) (Alessi, 2001). The inactivation of GSK3 by Akt promotes glucose storage as glycogen. Insulin also directly controls the activities of a set of metabolic enzymes by phosphorylation and dephosphorylation events and regulates the expression of genes encoding hepatic enzymes involved in gluconeogenesis. Forkhead transcription factor box A (Foxa) proteins, which is excluded from the nucleus following phosphorylation by Akt, play a central role in maintaining normal glucose homeostasis by regulating gene expression of rate-limiting enzymes of gluconeogenesis and glycogenolysis in the liver and kidney, including phosphoenolpyruvatecarboxykinase (PEPCK) and glucose-6-phosphatase (G6Pase) (Wolfrum et al., 2003) . A key action of insulin is to stimulate glucose uptake into cells by inducing translocation of the glucose transporter, GLUT4, from intracellular storage to the plasma membrane. PI3-kinase/Aktis known to play an important role in this translocation and, as a result, glucose enters the cell (Wilcox, 2005).

In addition to the PI3-kinase pathway for GLUT4 translocation, there is a second and independent way for GLUT4 to be recruited to the plasma membrane (Fig. 2). Specifically, insulin receptor activation leads to the phosphorylation of a proto-oncogene product, Casitas B-lineage lymphoma (Cbl), which is associated with the adaptor protein CAP (Cbl-associated protein). Following phosphorylation, the Cbl-CAP complex translocates to lipid rafts in the plasma membrane. $\mathrm{Cbl}$ then interacts with the adaptor protein Crk, which is constitutively associated with the Rho-family guanine nucleotide exchange factor, C3G. This protein, in turn, activates members of the TC10 GTP-binding protein family, which promote GLUT4 translocation to the plasma membrane through the activation of as-yet-unknown adaptor molecules (Saltiel and Kahn, 2001).

\section{MIRNAS IN GLUCOSE HOMEOSTASIS}

\section{miRNAs in insulin production and secretion}

Normal insulin secretion and action maintain appropriate levels of glucose in the body, and miRNAs have emerged as a new layer of gene regulation in glucose homeostasis. Poy et al. (Poy et al., 2009) identified several miRNAs that are selectively expressed in pancreatic endocrine cell lines. Among these is miR-375, which was first cloned from a mouse insulinoma pancreatic $\beta$-cell line (MIN6 cells) and identified as the most abundant, evolutionarily conserved, islet-specific miRNA (Poy et al., 2004) . The miR-375 gene is located on chromosome 2 in humans and chromosome 1 in mice and sits within an intergenic region between the cryba2 (b-A2 crystallin, an eye lens component) and CCDC108 (coiled-coil domain-containing protein 108) genes, a genomic region conserving the synteny between humans and mice (Baroukh and Van Obberghen, 2009). miR-375 regulates glucose-stimulated insulin secretion in a negative manner, while its antagomiRs (small synthetic chemically engineered oligonucleotide used to silence endogenous miRNAs) enhance insulin secretion (Tang et al., 2008). One of the targets of miR-375 has been identified as myotrophin (Mtpn), a protein involved in the distal stage of insulin secretion in pancreatic $\beta$-cells (Fig. 3). The exact mechanism of Mtpn regulating insulin secretion remains unclear, yet it has been proposed that this process is mediated by NF-KB and/or its interaction with an actin-capping protein, CapZ, which inhibits actin polymerization (by inhibiting F-actin assembly) and induces exocytosis of insulin granules (Hennessy and O'Driscoll, 2008; Tang et al., 2008). Mice with a homozygous deletion of miR-375 appear to have hyperglycemia due to decreased total pancreatic $\beta$-cell mass and insulin levels (Poy et al., 2007), concomitantly increasing the level of total pancreatic a-cell numbers, fasting and fed plasma glucagon levels, and gluconeogenesis and hepatic glucose output (Poy et al., 2009). In contrast, the pancreatic islets of obese (ob/ob) mice, a model of increased $\beta$-cell mass, exhibit increased expression of miR-375. Genetic deletion of miR-375 in ob/ob mice further diminishes the proliferative capacity of the endocrine pancreas and results in a more severe diabetic phenotype (Poy et al., 2009). This suggests that, in addition to regulating insulin secretion, miR-375 plays an important role in pancreatic $\beta$-cell development. PDK1 is another target of miR-375 expressed in the pancreatic islet cell. Overexpression of miR-375 in INS-1E insulinoma cells and rat primary islets $\beta$-cell lines leads to lower levels of PDK1 protein, accompanied by reduced activation of downstream signaling, including the PI3K-Akt cascade and GSK3 phosphorylation (EI Ouaamari et al., 2008).

Lynn and colleagues (Lynn et al., 2007) generated a mouse model in which miRNA biogenesis was globally blocked through deletion of a conditional Dicer allele. When Dicer is deleted at an early stage of pancreatic development using the pancreatic duodenal homeobox-1 $[\mathrm{Pdx}-1]$ promoter, serious developmental defects were observed in all pancreatic cell types, suggesting a critical role for miRNAs during pancreatic development. However, when Dicer was deleted later in development using the rat insulin promoter, little effect was seen, either on pancreatic morphology or on $\beta$-cell maintenance. This is surprising, as these $\beta$-cells are expected to lack all miRNAs. These results clearly demonstrate the importance of miRNAs during development, yet their precise role in the adult islet remains elusive. In another study, 


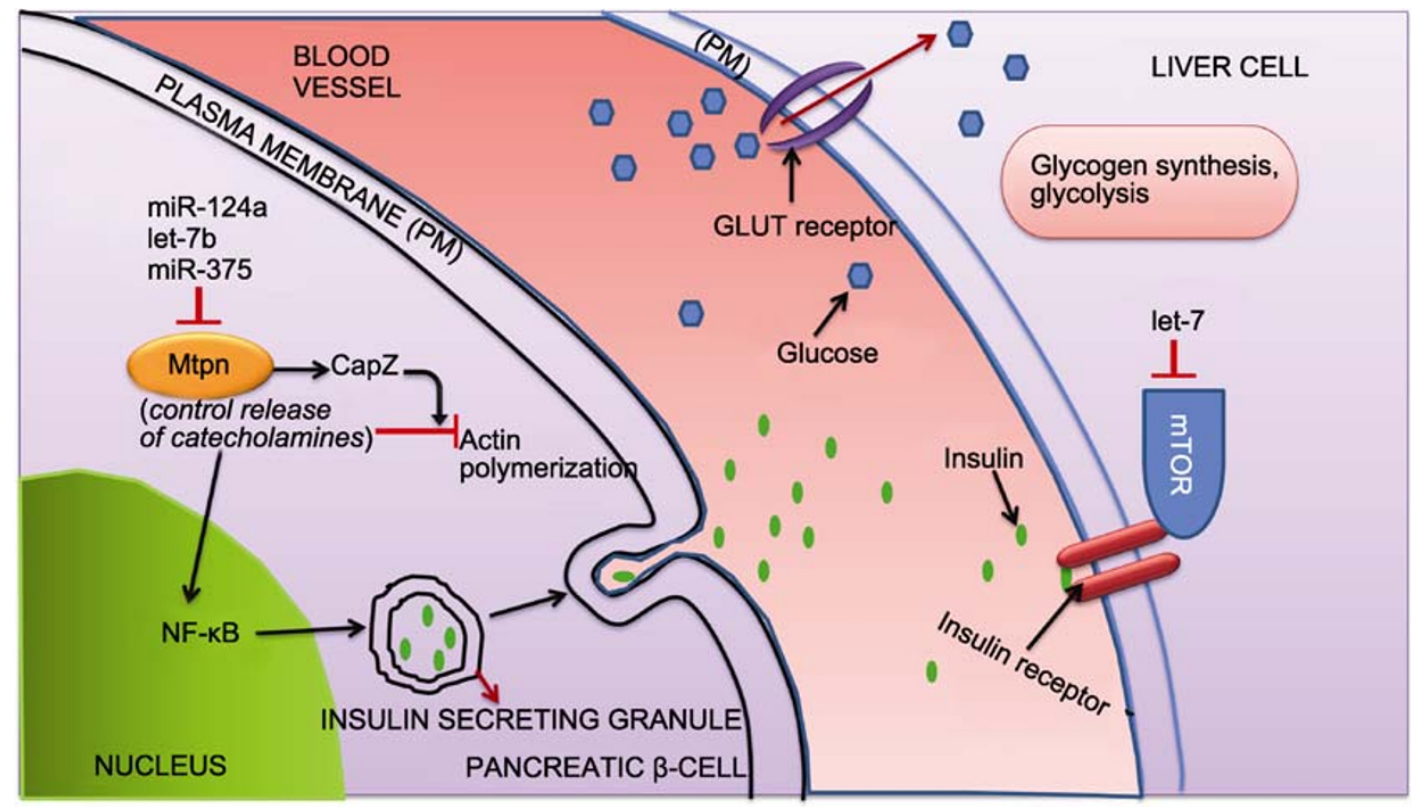

Figure 3. Schematic diagram showing the potential of miRNAs as biomarkers or drug targets. miR-375, miR-124a, and let-7b down-regulate myotrophin (Mtpn), a protein involved in the distal stage of insulin secretion in pancreatic $\beta$ cells. Mtpn controls release of the neurotransmitter catecholamine and is involved in insulin vesicle exocytosis. Mtpn interacts with an actin-capping protein, CapZ, which inhibits actin polymerization (inhibiting F-actin assembly) and induces exocytosis of insulin granules.

Kalis and his coworkers (Kalis et al., 2011) demonstrated that targeted disruption of the Dicer1 gene specifically in $\beta$-cells using the Cre-lox system controlled by the rat insulin promoter (RIP) leads to progressive hyperglycemia and full-blown diabetes mellitus in adult mice. This is in contrast to the data of Lynn and colleagues. Different genetic background and/or the extent of Dicer1 deletion could account for the discrepancies.

Mtpn expression is also regulated by several other miRNAs, including miR-124a and let-7b (Krek et al., 2005). miR-124a, which is found in greatest abundance in brain and nervous tissue, is also abundant in pancreatic $\beta$-cells (Conaco et al., 2006; Krichevsky et al., 2006). In mice, miR-124a has three precursor hairpin sequences: miR-124a-1 on chromosome 14, miR-124a-2 on chromosome 3, and miR-124a-3 on chromosome 2, and all three miR-124a genes have closely related predicted human homologues (Poy et al., 2007). In a recent study, Baroukh et al. carried out miRNA expression profiling at two key stages of mouse embryonic pancreatic development, e14.5 and e18.5. miR-124a-2 expression is strikingly increased at gestational age e18.5 compared to e14.5 in the developing pancreas, suggesting a possible role in $\beta$-cell development (Baroukh et al., 2007). One of the established targets for miR-124a is Foxa2, a transcription factor regulating $\beta$-cell differentiation, pancreatic development, glucose metabolism, and insulin secretion (Wang et al., 2002; Baroukh et al., 2007). Foxa2 exercises its role in endocrine pancreatic development by velopment by regulating the expression of the $\beta$-cell-specific transcription factor Pdx-1 and the two subunits of the KATP channel, Kir6.2 (the inwardly-rectifying potassium channel) and Sur-1 (the sulfonylurea receptor) (Baroukh et al., 2007). Another group showed that miR-124a modulates the expression of secretory pathway proteins involved in the insulin exocytosis machinery, such as synaptosomal-associated protein 25 (SNAP25), Ras-related protein Rab-3A (Rab3A), and synapsin-1A, to affect $\beta$-cell secretion (Baroukh et al., 2007; Lovis et al., 2008a).

miR-9, which is expressed in the pancreatic $\beta$-cells, is a regulator of insulin exocytosis. Plaisance et al. found that miR-9 inhibits insulin secretion by repressing the expression of the Onecut2 transcription factor and thereby increasing the levels of granuphilin (also known as SIp4), which down-regulates insulin secretion (Plaisance et al., 2006). Onecut2 inhibits the expression of granuphilin by directly binding to its promoter (Plaisance et al., 2006). Granuphilin is a RabGTPase effector associated with $\beta$-cell secretory granules that exerts a negative control on insulin release (Coppola et al., 2002). miR-96 also modulates granuphilin levels to regulate insulin secretion. In addition, miR-96 decreases the expression of Noc2, a Rab effector protein involved in secretion (Lovis et al., 2008a).

\section{miRNAs in insulin action}

Besides having roles in insulin production and secretion, 
miRNAs also control insulin signaling in tissues targeted by insulin. The miR-29 gene family is highly expressed in skeletal muscle, liver, and adipose tissues of diabetic Goto-Kakizaki (GK) rats, a non-obese model of T2D. miR-29 includes three paralogs: miR-29a, miR-29b, and miR-29c. Adenovirus-mediated overexpression of $\mathrm{miR}-29 \mathrm{a} / \mathrm{b} / \mathrm{c}$ in 3T3-L1 adipocytes, a murine insulin-responsive cell line, inhibits insulin-stimulated glucose uptake and Akt activation. High levels of miR-29 lead to insulin resistance, mimicking the insulin resistance in cells incubated with high concentrations of glucose and insulin (He et al., 2007). miR-29 represses the expression of insulin-induced gene 1 (Insig1), an ER membrane protein that is involved in control of cholesterol biosynthesis, and caveolin 2 (Cav2). Insig1 is a significant integrator of nutrient and hormonal signals, which is induced by insulin and regulates cleavage of sterol regulatory element-binding protein/adipocyte determination and differentiation factor 1 (SREBP, also known as ADD1) and formation of its nuclear isoform (Vikman et al., 2006; He et al., 2007). Cav2 is a major component of the inner surface of caveolae (small invaginations of the plasma membrane), which interacts directly with heterotrimeric guanine nucleotide-binding proteins ( $G$ proteins) and regulates their activity. Cav2 is highly expressed in white adipose tissue and is induced during adipocyte differentiation (Scherer et al., 1996). It has been found that overexpression of miR-29 causes a decrease in the levels of Insig1 and Cav2 proteins. The third target of miR-29 is syntaxin-1, a participant in GLUT4 vesicle fusion to the plasma membrane via its interaction with Munc18 (Scherer et al., 1996; He et al., 2007). Syntaxin-1 is required for rapid exocytosis of insulin in pancreatic $\beta$-cells (Vikman et al., 2006), and high glucose and lipid levels result in disappearance of syntaxin-1 in T2D (Vikman et al., 2006; He et al., 2007).

In the mouse genome, 12 genes encode members of the let-7 family includes nine slightly different miRNAs (let-7a to let-7i). Frost and Olson generated a transgenic mouse line with Cre-inducible activation of let-7a, let-7d, and let-7f expression (Frost and Olson, 2011). Whole-body or pancreas-specific overexpression of let-7 in mice resulted in impaired glucose tolerance and reduced insulin secretion. Let-7 overexpression causes lower fat mass and smaller mouse body weight and body size. Inhibition of the let-7 family prevents impaired glucose tolerance in mice with diet-induced obesity, partially by increasing insulin sensitivity in liver and muscle. In addition, let-7 inhibition in mice on a high-fat diet also leads to augmented lean and muscle mass, but not increased fat mass, and reduces ectopic fat deposition in the liver (Frost and Olson, 2011). In a separate study, Zhu et al generated a mouse line overexpressing let-7g under induction and these animals have a similar phenotype of glucose metabolism as the one with the let-7a/d/f transgene (Zhu et al., 2011). Target genes repressed by let-7 include IGF1R, INSR, IRS2, HMGA2, and IGF2BP2. These data support that let-7 is a regulator of glucose metabolism and that the let-7 family is a potential target for T2D.

Lovis et al. reported that altered miRNA pattern contributes to free fatty acid (FFA)-induced pancreatic $\beta$-cell dysfunction by analyzing miRNA expression in insulin-secreting cell lines or pancreatic islets diabetic $d b / d b m i c e$ exposed to palmitate(Lovis et al., 2008b). Several miRNAs were found to be altered by palmitate in MIN6B1 cells using microarray analysis. Of these, miR-34a and miR-146 levels were found to be increased and analyzed for their further role in the pancreas. Supportively, their levels were also elevated in the islets of diabetic $d b / d b$ mice (Lovis et al., 2008b). miR-34a is upregulated by p53 activation that is an inducer of apoptosis. FFA-mediated regulation of p53 via miR-34a, is therefore a novel mode of regulation of pancreatic apoptosis initiated by FFA. Within the islets, miR-34a affects hormone secretion by targeting VAMP2, a vesicle protein that is involved in insulin exocytosis. miR-146 acts by targeting IRAK1 (Interleukin-1 receptor-associated kinase 1) and TRAF6 (TNF receptor associated factor 6 ), both of which are involved in pancreatic $\beta$-cell death (Labbaye and Testa, 2012). These data suggest that some detrimental effect of FFA on $\beta$-cells is caused by alterations in the level of specific miRNAs. An ensuing study implicates miR-34a and miR-146a, as well as miR-21 as novel players in $\beta$-cell failure elicited by proinflammatory cytokines during the development of peri-insulitis that precedes overt diabetes in NOD mice (Roggli et al., 2010).

Of the two genes encoding insulin receptor substrate proteins (IRS1 and IRS2), only IRS1 has been identified as a target of miRNAs, specifically miR-145 (Shi et al., 2007). Overexpression of miR-145 in human colon cancer cells caused a decrease in IRS-1 protein levels without affecting IRS1 mRNA levels. The role of miR-145 in diabetes needs further investigation.

miR-143 has been shown to be upregulated during adipocyte differentiation (Esau et al., 2004), while its inhibition elevates the expression of adipocyte-specific genes (insulin-sensitive glucose transporter [GLUT4], hormone-sensitive lipase [HSL], fatty acid-binding protein [aP2], and peroxisome proliferator-activated receptor gamma 2 [PPAR-y2]) and leads to accumulation of triglycerides (Esau et al., 2004). Knockdown of miR-143 leads to upregulation of the mitogen-activated protein kinase ERK5 (also known as BMK1 or MAPK7) (Esau et al., 2004). Jordan and his colleagues demonstrated that expression of miR-143 is upregulated in the liver tissues of obese mice (Jordan et al., 2011). Transgenic overexpression of miR-143 attenuates insulin-stimulated AKT activation and glucose homeostasis. On the other hand, mice without miR-143 are protected from insulin resistance associated with obesity. They identified oxysterol-binding-protein-related protein 8 (ORP8) as the miR-143 target gene. This study underscores the role of miR-143 in obesity-induced insulin resistance and implicates the miR-143-ORP8 pathway as a potential target for T2D 
treatment (Jordan et al., 2011). miR-14 is found in Drosophila and regulates adipocyte droplet size and triacylglycerol levels (Xu et al., 2003). Deletion of miR-14 results in increased levels of triacylglycerol and diacylglycerol, whereas increases in miR-14 copy number has the opposite effect (Xu et al., 2003). miR-278 is another miRNA involved in energy homeostasis in Drosophila, and miR-278-mutant flies, in spite of having elevated insulin-production capacities, display increased circulatory glucose levels, which indicates a loss of insulin responsiveness (Teleman and Cohen, 2006). However, these two miRNAs have no homologues in mammals. In addition to the above mentioned miR-143, other miRNAs important for regulation of human and mouse adipocyte differentiation have been identified. Esau et al (2006) found that liver-specific miR-122 as a significant regulator of hepatic lipid metabolism. In normal mice, inhibition of miR-122 leads to reduced plasma cholesterol levels, increased hepatic fatty acid oxidation, and a decrease in hepatic fatty acid and cholesterol synthesis rates (Esau et al., 2006). Moreover, the circulatory cholesterol levels are also reduced, indicating that miR-122 is a significant modulator of plasma cholesterol levels (Baskerville and Bartel, 2005). miR-122 inhibition in a diet-induced obesity mouse model resulted in decreased plasma cholesterol levels and a significant improvement in liver steatosis (accumulation of fat in liver cells) accompanied by reductions in several lipogenic genes, such as phosphomevalonate kinase (Baskerville and Bartel, 2005). These results implicate miR-122 as a key regulator of cholesterol and fatty acid metabolism in the adult liver.

miR-103 and miR-107 are conserved in all vertebrate genomes and are located within introns of the pantothenate kinase (PANK) genes. They are predicted to affect multiple targets in pathways that involve cellular acetyl-CoA and lipid levels (Wilfred et al., 2007). miR-107 differs from miR-103 by a single nucleotide, while miR-103-1, miR-103-2, and miR-107 reside within the PANK3, PANK2, and PANK1 genes, respectively. PANK enzymes catalyze the rate-limiting step of pantothenate phosphorylation during the generation of coenzyme A (CoA), which is a critical cofactor of several enzymes involved in diverse metabolic pathways for synthesis of fatty acids, amino acids, cholesterol, pyruvate/lactate, glucose, and the Krebs cycle (Wilfred et al., 2007; Pandey et al., 2009). According to Trajkovski et al (2011), the expression of miR-103/107 is upregulated in obese mice. Inhibition of miR-103/107 leads to improved glucose homeostasis and insulin sensitivity while their overexpression in either liver or fat induces impaired glucose homeostasis. They identified caveolin-1 as a functional target gene of miR-103/107. These findings implicate miR-103/107 as potential targets for the treatment of T2D and obesity (Trajkovski et al., 2011).

Expression of miRNAs in islets, lever, and adipose of diabetic mice are profiled, providing support that obesity and genetics exert miRNA regulation (Zhao et al., 2009). The
Goto-Kakizaki (GK) rat is a well-studied non-obese spontaneous type 2 diabetes (T2D) animal model, Global profiling of 348 miRNAs in the islets of GK rats suggest there is little overlap of dysregulatedmiRNAs. This suggests that there may be species-specific function of miRNAs in T2D.

\section{MIRNAS IN DIABETIC COMPLICATIONS}

Diabetes causes complications in many organs, such as heart, kidney, eye, and foot, and miRNAs are involved in many of these complications.

\section{Diabetic cardiomyopathy}

One of the most abundant miRNAs present in adult cardiac and skeletal muscle in mammals, miR-133, plays a critical role in regulating myogenesis (Carè et al., 2007). The change of miR-133 levels in heart is associated with two consequences: a long QT syndrome (LQTS) and cardiac hypertrophy (Carè et al., 2007). The QT interval is a measure of the time between the start of the $Q$ wave (representing depolarization of the interventricular septum) and the end of the T wave (representing repolarization or recovery of the ventricles) in the heart's electrical cycle. LQTS is a life-threatening disorder that affects the heart's electrical system and may lead to fainting, cardiac arrest, and possibly sudden death (Carè et al., 2007).

Cardiac hypertrophy is characterized by a thickening of the heart muscle (myocardium) that causes a decrease in size of the left and right ventricles and is associated with electrical remodeling. A common cause of this pathology is high blood pressure (hypertension) and heart valve stenosis (Tang et al., 2008), which are typical symptoms of long-term complications due to diabetes. Interestingly, the function of miR-133 in cardiac hypertrophy seems to be the opposite of its role in LQTS. While overexpression of miR-133 induces LQTS, down-regulation of miR-133 levels lead to cardiac hypertrophy. In vitro overexpression of miR-133 or miR-1 (both miRNAs are expressed by the same transcriptional unit) inhibits cardiac hypertrophy. Blocking of miR-133 function in vivo causes marked and sustained cardiac hypertrophy (Mishra et al., 2009). miR-133 exercises its function in cardiac hypertrophy through the suppression of RhoA, a GDP-GTP exchange protein that regulates cardiac hypertrophy, Cdc42, a signal transduction kinase implicated in hypertrophy, and Nelf-A (also known as WHSC2), a nuclear factor involved in cardiogenesis(Carè et al., 2007) (Fig. 4B). Sharing the same transcriptional unit as miR-133, miR-1 regulates cardiac arrhythmogenic potential by targeting $K C N J 2$ (encoding the $\mathrm{K}^{+}$ channel subunit Kir2.1) and GJA1 (encoding connexin 43) and slowing down cardiac conduction, resulting in depolarization of the cytoplasmic membrane (Yang et al., 2007). In a rat model of cardiac hypertrophy, hyperpolarization-activated cyclic nucleotide-gated channels encoded by HCN2 and 


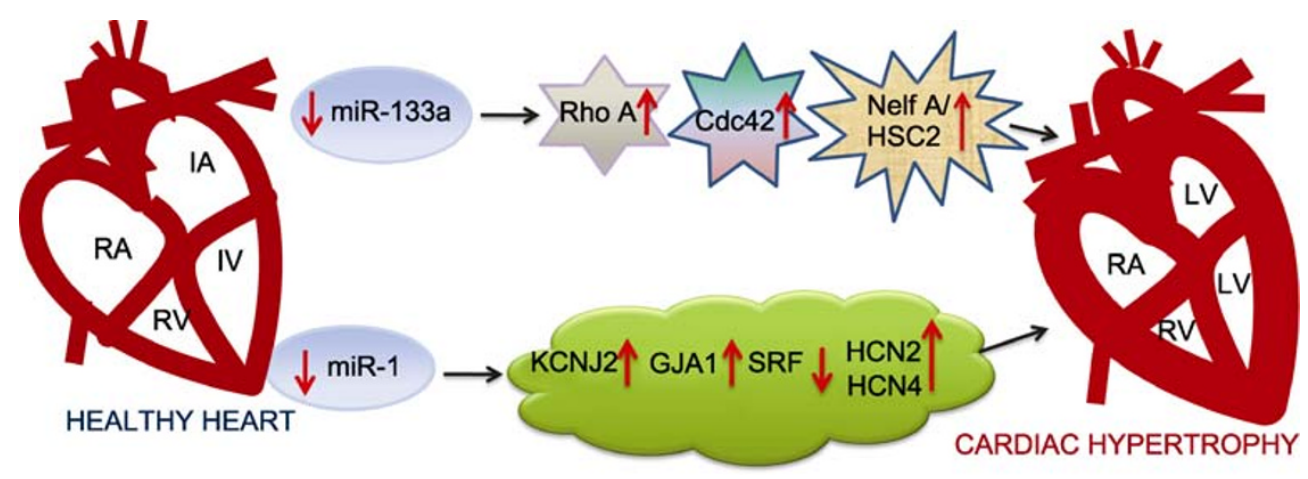

Figure 4. Schematic diagram of the role of miR-133a and miR-1 in cardiac hypertrophy. Down-regulation of miR-133a and miR-1 in healthy hearts increases Rho A, Cdc42, and Nelf A levels and results in cardiac hypertrophy.

HCN4 are considerably upregulated, which is accompanied by significant reductions in miR-1/miR-133 levels (Luo et al., 2008). HCN channels generate If (hyperpolarization-activated current or, simply, pacemaker current) which plays a crucial role in cardiac pacemaker activity. Four different $\mathrm{HCN}$ genes have been identified (HCN1-4) (Moosmang et al., 2001). $\mathrm{HCN} 1$ is the most rapidly acting channel, HCN2 and HCN3 exhibit intermediate kinetics, while $\mathrm{HCN} 4$ is the slowest-acting channel (Moosmang et al., 2001). In animal models of cardiac hypertrophy and heart failure, HCN2 and HCN4 are overexpressed and If is strikingly increased (Michels et al., 2005). With overexpression of $\mathrm{miR}-133 / \mathrm{miR}-1$, there is significant reduction of HCN2 and HCN4 levels (Luo et al., 2008). In fact, miR-1 is overexpressed in individuals with coronary heart disease and its targeted overexpression in normal hearts manifests an identical phenotype that is associated with arrhythmias (Fig. 4).

Wang et al. reported that miR-320 is expressed in myocardial microvascular endothelial cells and involved in regulation of insulin-like growth factor-1 in T2D rats (Wang et al., 2009). Of all the miRs whose levels are altered in diabetic myocardial microvascular endothelial cells (MMVECs), miR-320 is the most important, targeting angiogenic factors and their receptors, namely, VEGF, IGF-1, IGF-1R, and FGF (Wang et al., 2009)_all of which are mediators of diabetic cardiomyopathy. Elevation of miR-320 in diabetic MMVECs is accompanied by decreased cell proliferation and migration that is reversed with miR-320 inhibitors. These findings suggest that miRNAs are critical regulators of cardiac pathophysiology in diabetes.

\section{Diabetic nephropathy}

Diabetic complications are also associated with kidney, a vital organ involved in excretion of waste products and in homeostasis. Diabetic nephropathy (DN), also known as Kimmelstiel-Wilson syndrome or intercapillary glomerulonephritis, is a progressive kidney disease that causes kidney failure in patients with longstanding diabetes mellitus. The major characteristics of DN include glomerular basement membrane thickening, mesangial expansion and hypertrophy, and accumulation of extracellular matrix (ECM) proteins (Kato et al., 2007). Transforming growth factor $\beta 1$ (TGF- $\beta$ ) levels are increased under diabetic conditions in renal cells, including mesangial cells (MC), resulting in upregulation of ECM proteins, namely collagen $1 \alpha 1$ and 2 , and promotion of MC survival and oxidant stress (Kato et al., 2007). The ECM proteins are an integral part of the capillary basement membrane and mesangial matrix and include various types of collagens, laminin, fibronectin, and proteoglycans. The role of miR-192 in the kidney and in the pathogenesis of DN has been studied (Kato et al., 2007). Collagen 1 1 mRNA is increased by TGF- $\beta$ in mouse mesangial cells together with a decrease in the mRNA levels of E-box repressors, $\delta E F-1$ ( $\delta$-crystallin enhancer binding protein) and Smad-interacting protein 1 (SIP1). miR-192 levels are elevated by TGF- $\beta$ in these cells with SIP1 as a target (Kato et al., 2007). Both SIP1 and סEF-1 are repressors of Col1 $\alpha 2$ expression, and this repression is withdrawn under diabetic conditions initiated by TGF- $\beta$, which also down-regulates $\delta E F 1$ through unknown mechanisms. Down-regulation of SIP1 and $\delta E F 1$ collectively enhances the expression of Col1 $\alpha 2$ by de-repressing the E-box elements located on the Col1 $\alpha 2$ promoter (Kato et al., 2007). Upregulation of TGF- $\beta$ or miR-192 is observed in glomeruli isolated from streptozotocin-induced diabetic mice as well as in diabetic $d b / d b m i c e$ compared to corresponding non-diabetic controls (Kato et al., 2007; Stitt-Cavanagh et al., 2009). These findings suggest an important role for miR-192 in kidney and DN development. Fibronectin is another matrix protein that is excessively accumulated in diabetic nephropathy (Wang et al., 2008). This large glycoprotein consists of two similar polypeptide chains and is a key component of the mesangial matrix. It may exist in a soluble dimeric form, as oligomers, or as a highly insoluble fibrillar form in the extracellular matrix. The latter form has been shown to modulate various biological processes, such as cell adhesion, mi- 
gration, and differentiation (Pandey et al., 2009). Wang et al. (2008) reported that in cultured human and mouse mesangial cells exposed to high glucose and TGF- $\beta$ as well as in a mouse diabetic nephropathic model, miR-377 is consistently upregulated. This miRNA represses the expression of p21-activated kinase and superoxide dismutase, which enhances fibronectin production. Thus, overexpression of miR-377 indirectly leads to increased fibronectin protein production that accumulates in the kidney matrix, and this emerges as the phenotype of DN. miR-216 is also upregulated by TGF $\beta 1$ in experimental models of DN (Saal and Harvey, 2009) and targets Y-box protein-1 (YB-1), leading to diabetic glomeruli (Fig. 5).

\section{Diabetic retinopathy}

Complications of diabetes mellitus in the eye are known as diabetic retinopathy (DR), which causes damage to the retina and eventually leads to blindness. DR affects up to $80 \%$ of all patients with diabetes for 10 years or more and is the result of microvascular retinal changes. Major symptoms include pericyte death and thickening of the basement membrane, leading to incompetence of the vascular walls. Such damage changes the formation of the blood-retinal barrier and also makes the retinal blood vessels more permeable. Pericyte death is caused when hyperglycemia persistently activates protein kinase C- $\delta$ (PKC- $\delta$, encoded by Prkcd) and MAPK, which increases the expression of $\mathrm{SH} 2$ domain-containing phosphatase-1 (SHP-1), a protein tyrosine phosphatase. This signaling cascade leads to PDGF receptor dephosphorylation and a reduction in downstream signaling from this receptor, resulting in pericyte apoptosis (Geraldes et al., 2009). Kovacs et al. (2011) recently conducted miRNA expression profiling in the retina and in isolated retinal endothelial cells (RECs) of streptozotocin (STZ)-induced diabetic rats three months after the onset of diabetes (Kovacs et al., 2011). A large number of miRNAs are dysregulated in the retina and in the RECs of diabetic rats (Kovacs et al., 2011). A hyperglycemic environment and elevated expression of several growth factors have been found to be key mediators of DR (Kantharidis et al., 2011). Upregulation of NF-kB, VEGF, and p53-responsive miRNAs constitute key miRNA signatures, reflecting ongoing pathological changes of early DR (Kovacs et al., 2011). $\mathrm{NF}-\mathrm{kB}$, a key regulator of inflammatory immune responses, is known to be activated in the retina as early as two months after the onset of diabetes and plays important roles in the pathogenesis of DR. Kovacs et al. (2011) report that NF-KB downstream genes, including intercellular adhesion molecule-1 (ICAM-1) and monocyte chemotactic protein-1 (MCP-1), are increased in the retina of diabetic rats. A few miRNA-supregulated in the RECs of diabetic rats are known to be regulated by NF-kB, including miR-146, miR-155, miR-132,

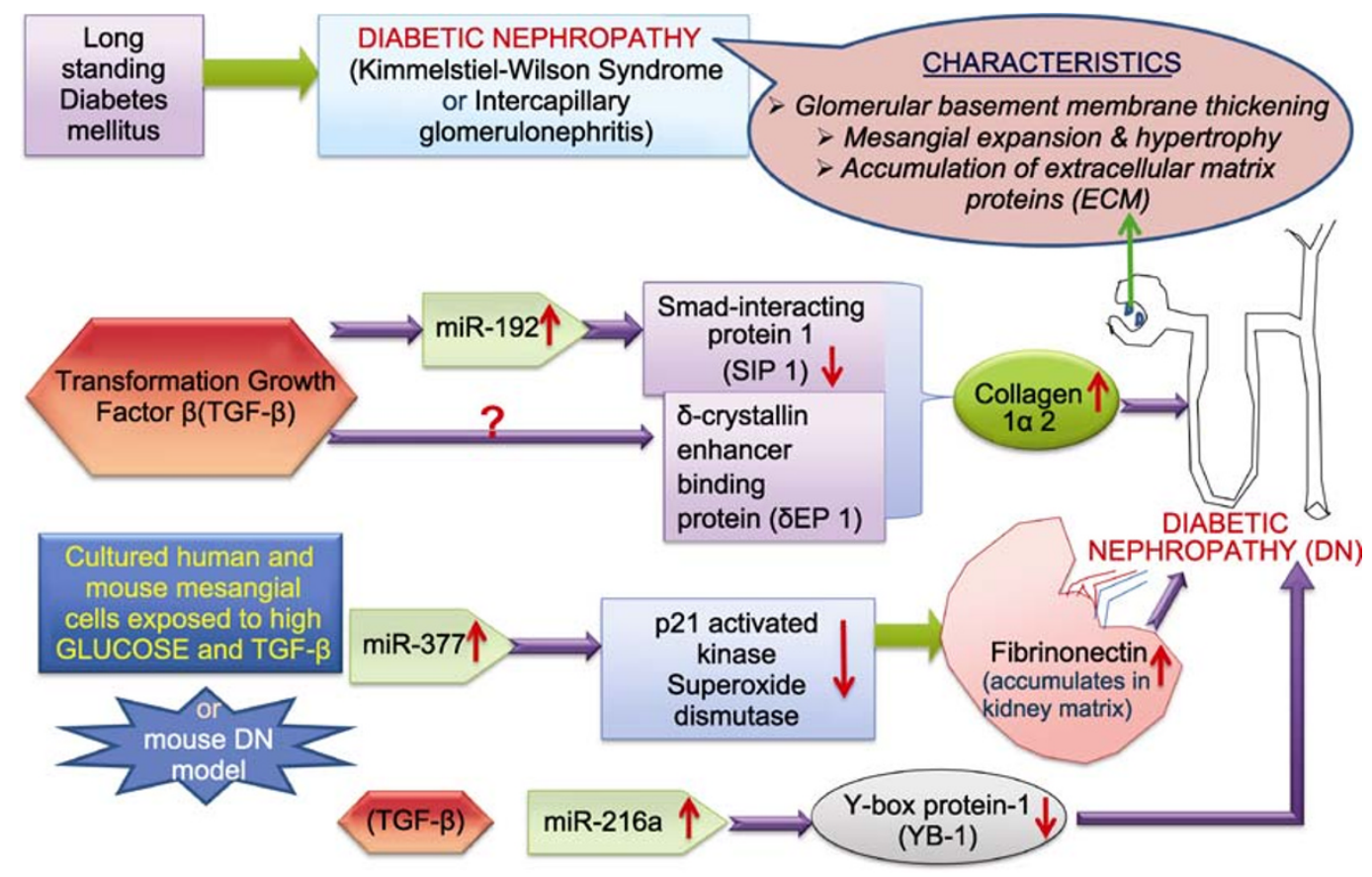

Figure 5. The role of miRNAs in diabetic complications of the kidney. Long-standing diabetes mellitus results in diabetic nephropathy. miR-192 and TGF- $\beta$ levels are elevated in mouse mesangial cells and, as a result, collagen $1 \alpha 2$ mRNA is increased together with a decrease in the mRNA levels of E-box repressors, $\delta E F-1$ ( $\delta$-crystallin enhancer binding protein) and Smad-interacting protein 1 (SIP1), gradually leading to the development of diabetic nephropathy. Proteins like fibronectin accumulate in cultured human and mouse mesengial cells exposed to high glucose and TGF- $\beta$. This effect is mediated by upregulation of miR-377 and miR-216a and a decrease in p21-activated kinase, superoxide dismutase, and YB-1 levels, resulting in diabetic nephropathy. 
and miR-21, suggesting amiRNA signature for NF-kB activation in diabetic RECs (Kovacs et al., 2011) (Fig. 6A). However, miR-146 also inhibits NF-KB activation by targeting two key adaptor molecules, IL-1 receptor-associated kinase 1 (IRAK1) and TNF receptor-associated factor 6 (TRAF6), of the MyD88-dependent IL-1R- or Toll-like receptor (TLR)-mediated NF-KB activation pathway in monocytes (Kovacs et al., 2011). This negative feedback regulation of $\mathrm{miR}-146$ by NF-KB activation may have important implications in $D R$, as inhibition of NF-KB activation in diabetic rats has been shown to inhibit development of DR. Similarly, another potent mitogen promoting angiogenesis and endothelial permeability, VEGF, is upregulated in the retina in diabetic animals and plays an important role in DR (Kantharidis et al., 2011; Kovacs et al., 2011). As VEGF is a predicted target of several miRNAs, including miR-200b/c, miR-29a/b/c, and miR-93, it would be interesting to determine whether these miRNAs are involved in DR. Long et al. reported that hyperglycemia led to reduced miR-93 expression by down-regulating the whole MCM7 host gene transcript, within which miR-93 resides, and that increased miR-93 expression prevented the hyperglycemia-induced expression of VEGF and its downstream signaling (Long et al., 2010).

\section{Diabetic neuropathic osteoarthropathy}

One of the major sources of morbidity and a leading cause of trauma for persons with diabetes mellitus is the group of foot disorders that may result. Ulceration, infection, gangrene, and amputation are significant complications of this disease. Another serious complication of long-standing diabetes, neuropathic osteoarthropathy (Charcot foot), can lead to the development of other limb-threatening disorders. Advanced glycation end products (AGEs) act through the receptor for AGEs (RAGE), activating inflammatory pathways. One of the endogenous physiological ligands of RAGE is $S 100 \mathrm{~b}$, a member of the $\mathrm{S} 100$ calgranulin family, and interaction of these ligands with RAGE is critical in inflammation, including in diabetic atherosclerosis (Kantharidis et al., 2011). miR-16 binds to the COX-2 mRNA 3'UTR in THP-1 monocytic cells and inhibits the binding of $S 100 \mathrm{~b}$ to the RAGE receptor (Kantharidis et al., 2011) (Fig. 5B). miR-503 has been identified as an important contributor to diabetes-induced impairment of endothelial function and angiogenesis, reducing cell growth and preventing the formation of blood vessels by suppressing Cyclin E1 and Cdc25a (Caporali et al., 2011) (Fig. 6B). miR-503 expression is remarkably higher, and

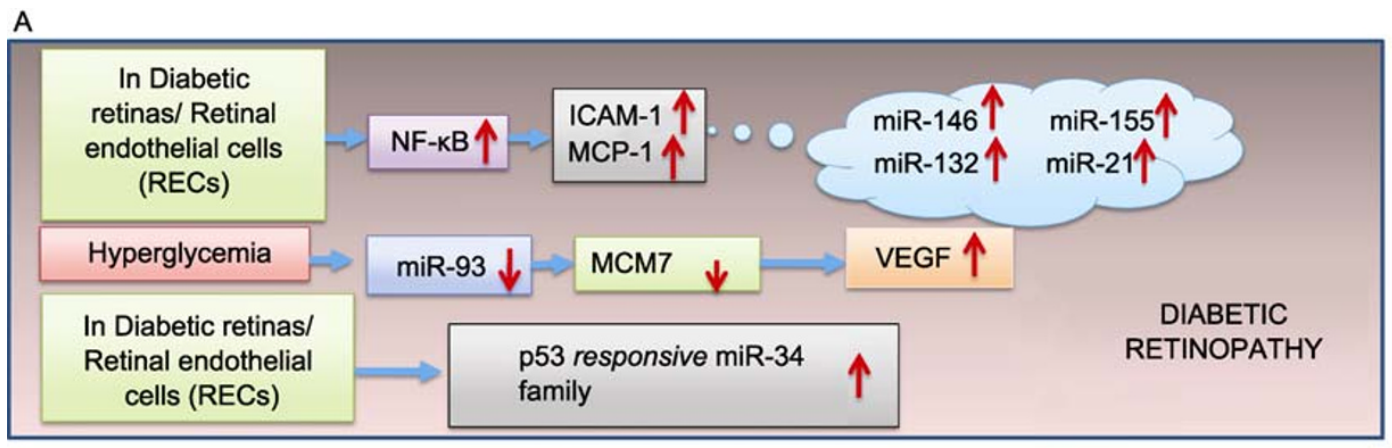

B

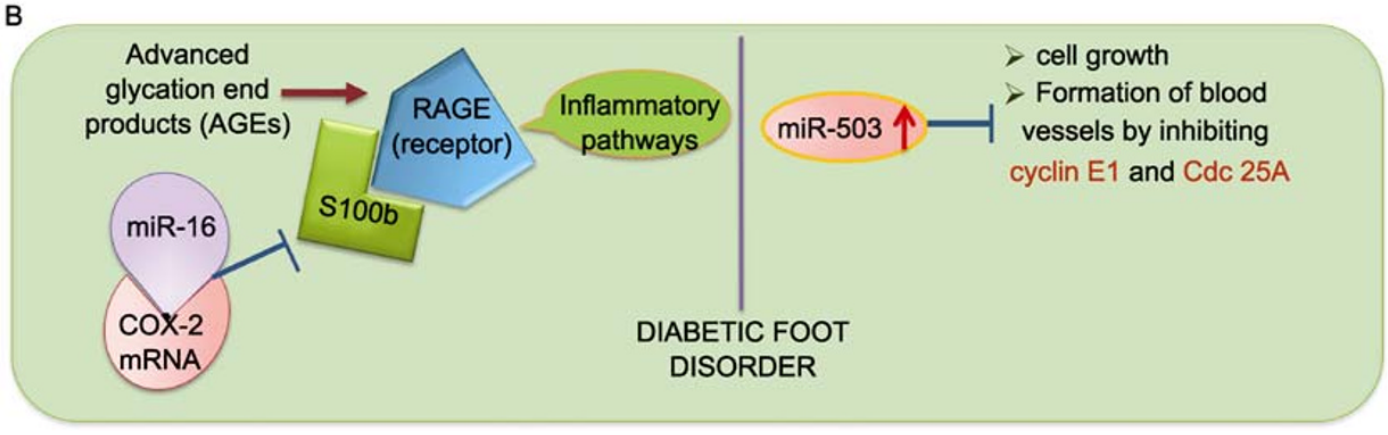

Figure 6. Schematic diagram showing the role of miRNAs in diabetic retinopathy and diabetic foot disorders.(A) In diabetic retinas or retinal endothelial cells, miR-146, miR-155, miR-132, and miR-21 are upregulated, with an increase in NF-k $\beta$, ICAM-1, and MCP-1 gene expression. Similarly, miR-93 is downregulated, causing a decrease in MCM7 gene expression and upregulation of VEGF. The p53-responsive miR-34 family is also upregulated in diabetic retinas. (B) miR-16 binds to the COX-2 mRNA 3'UTR in THP-1 monocytic cells and inhibits the binding of S100b to the RAGE receptor, resulting in diabetic foot disorder. miR-503 reduces cell growth and prevents the formation of blood vessels by suppressing Cyclin E1 and cdc25A and was found to be dramatically increased in diabetic complications. 


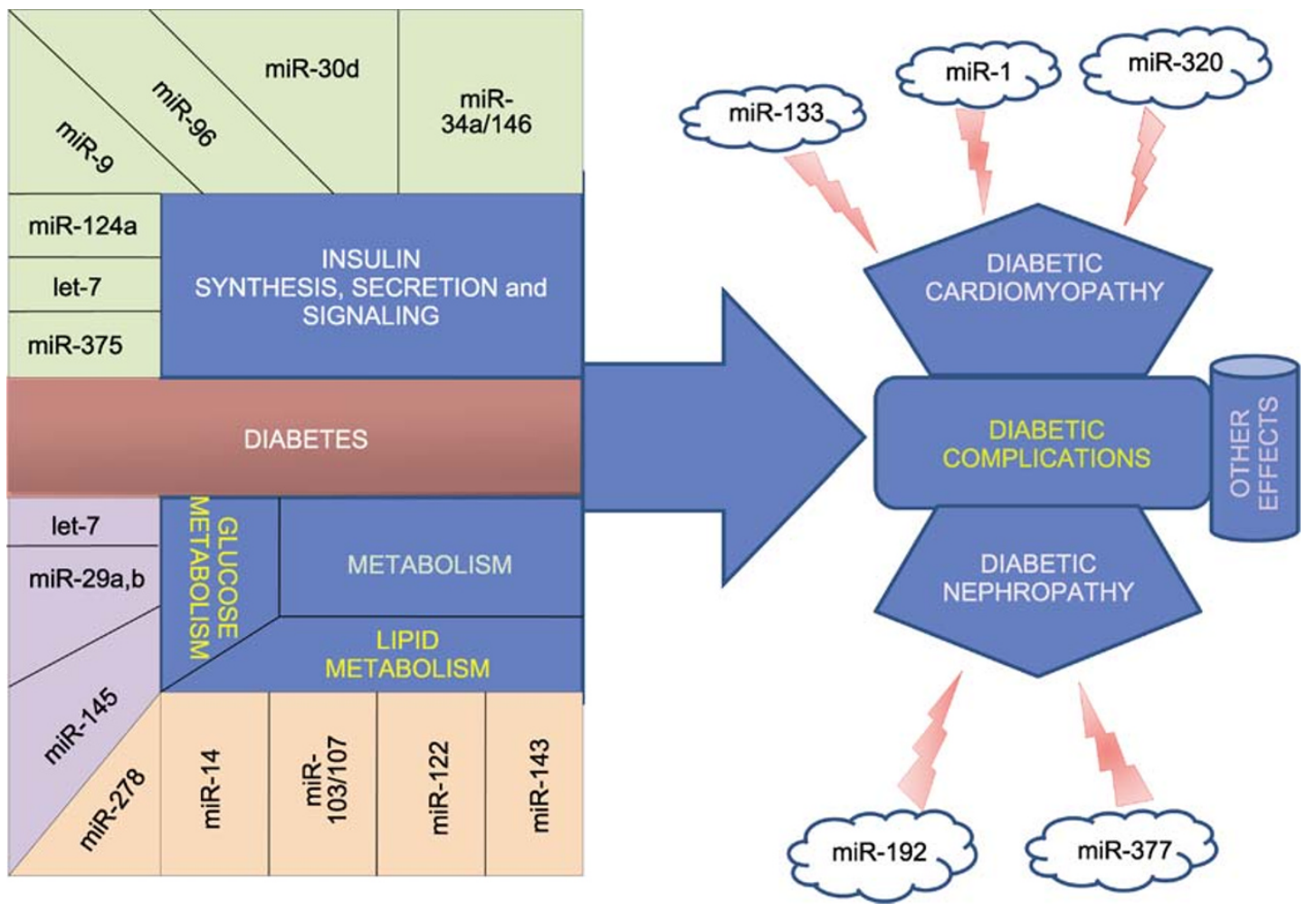

Figure 7. Schematic representation of miRNAs in glucose homeostasis. Upregulation or down-regulation of miR-375, let-7, miR-124a, miR-9, miR-96, miR-30d, miR-34a/146, miR-29a/b, mir-145, miR-278, miR-14, miR103/107, miR-122, or miR-143 may have drastic effects on insulin synthesis, secretion, signaling, and on other aspects of glucose and lipid metabolism, resulting in diabetes mellitus. miR-133, miR-1, miR-320, miR-192, and miR-377 may be involved in diabetic complications.

plasma miR-503 levels are also elevated in diabetic compared with healthy subjects. Inhibition of miR-503 improves the ability of endothelial cells to duplicate and form into networks of small blood vessels (Caporali et al., 2011). However, whether this miRNA plays a role in diabetic atherosclerosis remains to be established.

\section{CONCLUSION}

miRNAs are becoming one of the most fascinating areas of RNA biology because of their roles in the fine-tuning of physiological processes and their deregulation in human diseases. On the other hand, diabetes is one of the most challenging diseases in the modern era, with many serious complications. Various therapeutic applications have been developed to treat diabetes and diabetic-related complications, but none are completely effective, which suggests that our understanding of the disease is incomplete. Emerging evidence indicates that miRNAs play significant roles in insulin production, secretion, and action, as well as in glucose and lipid metabolism. The broad role of miRNAs as post-transcriptional gene regulators in diabetes and diabetic complications (Fig. 7) suggest that these miRNAs may serve as potential biomarkers and/or drug targets in prevention, treatment, and management of diabetes and its complications.

\section{REFERENCES}

Alessi, D.R. (2001). Discovery of PDK1, one of the missing links in insulin signal transduction. Colworth Medal Lecture. Biochem Soc Trans 29, 1-14.

Baroukh, N., Ravier, M.A., Loder, M.K., Hill, E.V., Bounacer, A., Scharfmann, R., Rutter, G.A., and Van Obberghen, E. (2007). MicroRNA-124a regulates Foxa2 expression and intracellular signaling in pancreatic $\beta$-cell lines. J Biol Chem 282, 19575-19588.

Baroukh, N.N., and Van Obberghen, E. (2009). Function of microRNA-375 and microRNA-124a in pancreas and brain. FEBS J 276, 6509-6521.

Bartel, D.P. (2004). MicroRNAs: genomics, biogenesis, mechanism, and function. Cell 116, 281-297.

Baskerville, S., and Bartel, D.P. (2005). Microarray profiling of microRNAs reveals frequent coexpression with neighboring miRNAs and host genes. RNA 11, 241-247.

Berezikov, E., Guryev, V., van de Belt, J., Wienholds, E., Plasterk, R.H.A., and Cuppen, E. (2005). Phylogenetic shadowing and computational identification of human microRNA genes. Cell 120, 21-24. 
Cai, X.Z., Hagedorn, C.H., and Cullen, B.R. (2004). Human microRNAs are processed from capped, polyadenylated transcripts that can also function as mRNAs. RNA 10, 1957-1966.

Caporali, A., Meloni, M., Vollenkle, C., Bonci, D., Sala-Newby, G.B., Addis, R., Spinetti, G., Losa, S., Masson, R., Baker, A.H., et al. (2011). Deregulation of microRNA-503 contributes to diabetes mellitus-induced impairment of endothelial function and reparative angiogenesis after limb ischemia. Circulation 123, 282-291.

Carè, A., Catalucci, D., Felicetti, F., Bonci, D., Addario, A., Gallo, P., Bang, M.L., Segnalini, P., Gu, Y.S., Dalton, N.D., et al. (2007). MicroRNA-133 controls cardiac hypertrophy. Nat Med 13, 613-618.

Conaco, C., Otto, S., Han, J.J., and Mandel, G. (2006). Reciprocal actions of REST and a microRNA promote neuronal identity. Proc Natl Acad Sci U S A 103, 2422-2427.

Coppola, T., Frantz, C., Perret-Menoud, V., Gattesco, S., Hirling, H., and Regazzi, R. (2002). Pancreatic $\beta$-cell protein granuphilin binds Rab3 and Munc-18 and controls exocytosis. Mol Biol Cell 13, 1906-1915.

Dieci, G., Fiorino, G., Castelnuovo, M., Teichmann, M., and Pagano, A. (2007). The expanding RNA polymerase III transcriptome. Trends Genet 23, 614-622.

El Ouaamari, A., Baroukh, N., Martens, G.A., Lebrun, P., Pipeleers, D., and van Obberghen, E. (2008). miR-375 targets 3'-phosphoinositide-dependent protein kinase-1 and regulates glucose-induced biological responses in pancreatic $\beta$-cells. Diabetes 57, 2708-2717.

Esau, C., Davis, S., Murray, S.F., Yu, X.X., Pandey, S.K., Pear, M., Watts, L., Booten, S.L., Graham, M., McKay, R., et al. (2006). miR-122 regulation of lipid metabolism revealed by in vivo antisense targeting. Cell Metab 3, 87-98.

Esau, C., Kang, X.L., Peralta, E., Hanson, E., Marcusson, E.G., Ravichandran, L.V., Sun, Y.Q., Koo, S., Perera, R.J., Jain, R., et al. (2004). MicroRNA-143 regulates adipocyte differentiation. J Biol Chem 279, 52361-52365.

Frost, R.J.A., and Olson, E.N. (2011). Control of glucose homeostasis and insulin sensitivity by the Let-7 family of microRNAs. Proc Natl Acad Sci U S A 108, 21075-21080.

Geraldes, P., Hiraoka-Yamamoto, J., Matsumoto, M., Clermont, A., Leitges, M., Marette, A., Aiello, L.P., Kern, T.S., and King, G.L. (2009). Activation of PKC- $\delta$ and SHP-1 by hyperglycemia causes vascular cell apoptosis and diabetic retinopathy. Nat Med 15, 1298-1306.

He, A.B., Zhu, L.L., Gupta, N., Chang, Y.S., and Fang, F.D. (2007). Overexpression of micro ribonucleic acid 29, highly up-regulated in diabetic rats, leads to insulin resistance in 3T3-L1 adipocytes. Mol Endocrinol 21, 2785-2794.

Hennessy, E., and O'Driscoll, L. (2008). Molecular medicine of microRNAs: structure, function and implications for diabetes. Expert Rev Mol Med 10, e24.

Jordan, S.D., Krüger, M., Willmes, D.M., Redemann, N., Wunderlich, F.T., Brönneke, H.S., Merkwirth, C., Kashkar, H., Olkkonen, V.M., Böttger, T., et al. (2011). Obesity-induced overexpression of miRNA-143 inhibits insulin-stimulated AKT activation and impairs glucose metabolism. Nat Cell Biol 13, 434-446.

Kalis, M., Bolmeson, C., Esguerra, J.L.S., Gupta, S., Edlund, A., Tormo-Badia, N., Speidel, D., Holmberg, D., Mayans, S., Khoo,
N.K.S., et al. (2011). Beta-cell specific deletion of Dicer1 leads to defective insulin secretion and diabetes mellitus. PloS One 6, e29166.

Kantharidis, P., Wang, B., Carew, R.M., and Lan, H.Y. (2011). Diabetes complications: the microRNA perspective. Diabetes 60 , 1832-1837.

Kato, M., Zhang, J., Wang, M., Lanting, L., Yuan, H., Rossi, J.J., and Natarajan, R. (2007). MicroRNA-192 in diabetic kidney glomeruli and its function in TGF-beta-induced collagen expression via inhibition of E-box repressors. Proc Natl Acad Sci U S A 104, 3432-3437.

Kovacs, B., Lumayag, S., Cowan, C., and Xu, S.B. (2011). MicroRNAs in early diabetic retinopathy in streptozotocin-induced diabetic rats. Invest Ophthalmol Vis Sci 52, 4402-4409.

Krek, A., Grün, D., Poy, M.N., Wolf, R., Rosenberg, L., Epstein, E.J., MacMenamin, P., da Piedade, I., Gunsalus, K.C., Stoffel, M., et al. (2005). Combinatorial microRNA target predictions. Nat Genet 37, 495-500.

Krichevsky, A.M., Sonntag, K.C., Isacson, O., and Kosik, K.S. (2006). Specific microRNAs modulate embryonic stem cell-derived neurogenesis. Stem Cells 24, 857-864.

Kumar, M., Lu, Z., Takwi, A.A.L., Chen, W., Callander, N.S., Ramos, K.S., Young, K.H., and Li, Y. (2011). Negative regulation of the tumor suppressor p53 gene by microRNAs. Oncogene 30 , 843-853.

Labbaye, C., and Testa, U. (2012). The emerging role of MIR-146A in the control of hematopoiesis, immune function and cancer. $J$ Hematol Oncol 5, 13.

Lee, R.C., Feinbaum, R.L., and Ambros, V. (1993). The C. elegans heterochronic gene lin-4 encodes small RNAs with antisense complementarity to lin-14. Cell 75, 843-854.

Long, J.Y., Wang, Y., Wang, W.J., Chang, B.H.J., and Danesh, F.R. (2010). Identification of microRNA-93 as a novel regulator of vascular endothelial growth factor in hyperglycemic conditions. J Biol Chem 285, 23457-23465.

Lovis, P., Gattesco, S., and Regazzi, R. (2008a). Regulation of the expression of components of the exocytotic machinery of insulin-secreting cells by microRNAs. Biol Chem 389, 305-312.

Lovis, P., Roggli, E., Laybutt, D.R., Gattesco, S., Yang, J.Y., Widmann, C., Abderrahmani, A., and Regazzi, R. (2008b). Alterations in microRNA expression contribute to fatty acid-induced pancreatic $\beta$-cell dysfunction. Diabetes 57, 2728-2736.

Luo, X.B., Lin, H.X., Pan, Z.W., Xiao, J.N., Zhang, Y., Lu, Y.J., Yang, B.F., and Wang, Z.G. (2008). Down-regulation of $m i R-1 / m i R-133$ contributes to re-expression of pacemaker channel genes HCN2 and HCN4 in hypertrophic heart. J Biol Chem 283, 20045-20052.

Lynn, F.C., Skewes-Cox, P., Kosaka, Y., McManus, M.T., Harfe, B.D., and German, M.S. (2007). MicroRNA expression is required for pancreatic islet cell genesis in the mouse. Diabetes 56, 2938-2945.

Michels, G., Er, F., Khan, I., Sudkamp, M., Herzig, S., and Hoppe, U.C. (2005). Single-channel properties support a potential contribution of hyperpolarization-activated cyclic nucleotide-gated channels and If to cardiac arrhythmias. Circulation 111, 399-404.

Mishra, P.K., Tyagi, N., Kumar, M., and Tyagi, S.C. (2009). MicroRNAs as a therapeutic target for cardiovascular diseases. J 
Cell Mol Med 13, 778-789.

Moosmang, S., Stieber, J., Zong, X.G., Biel, M., Hofmann, F., and Ludwig, A. (2001). Cellular expression and functional characterization of four hyperpolarization-activated pacemaker channels in cardiac and neuronal tissues. Eur J Biochem 268, 1646-1652.

Muhonen, P., and Holthofer, H. (2009). Epigenetic and microRNA-mediated regulation in diabetes. Nephrol Dial Transplant 24, 1088-1096.

Okamura, K., Hagen, J.W., Duan, H., Tyler, D.M., and Lai, E.C. (2007). The mirtron pathway generates microRNA-class regulatory RNAs in Drosophila. Cell 130, 89-100.

Pandey, A.K., Agarwal, P., Kaur, K., and Datta, M. (2009). MicroRNAs in diabetes: tiny players in big disease. Cell Physiol Biochem 23, 221-232.

Plaisance, V., Abderrahmani, A., Perret-Menoud, V., Jacquemin, P., Lemaigre, F., and Regazzi, R. (2006). MicroRNA-9 controls the expression of Granuphilin/SIp4 and the secretory response of insulin-producing cells. J Biol Chem 281, 26932-26942.

Poy, M.N., Eliasson, L., Krutzfeldt, J., Kuwajima, S., Ma, X.S., Macdonald, P.E., Pfeffer, S., Tuschl, T., Rajewsky, N., Rorsman, P., et al. (2004). A pancreatic islet-specific microRNA regulates insulin secretion. Nature 432, 226-230.

Poy, M.N., Hausser, J., Trajkovski, M., Braun, M., Collins, S., Rorsman, P., Zavolan, M., and Stoffel, M. (2009). miR-375 maintains normal pancreatic $\alpha$ - and $\beta$-cell mass. Proc Natl Acad Sci U S A 106, 5813-5818.

Poy, M.N., Spranger, M., and Stoffel, M. (2007). microRNAs and the regulation of glucose and lipid metabolism. Diabetes Obes Metab 9(Suppl 2), 67-73.

Roggli, E., Britan, A., Gattesco, S., Lin-Marq, N., Abderrahmani, A., Meda, P., and Regazzi, R. (2010). Involvement of microRNAs in the cytotoxic effects exerted by proinflammatory cytokines on pancreatic $\beta$-cells. Diabetes 59, 978-986.

Ruby, J.G., Jan, C.H., and Bartel, D.P. (2007). Intronic microRNA precursors that bypass Drosha processing. Nature 448, 83-86.

Saal, S., and Harvey, S.J. (2009). MicroRNAs and the kidney: coming of age. Curr Opin Nephrol Hypertens 18, 317-323.

Saltiel, A.R., and Kahn, C.R. (2001). Insulin signalling and the regulation of glucose and lipid metabolism. Nature 414, 799-806.

Scherer, P.E., Okamoto, T., Chun, M., Nishimoto, I., Lodish, H.F., and Lisanti, M.P. (1996). Identification, sequence, and expression of caveolin-2 defines a caveolin gene family. Proc Natl Acad Sci U S A 93, 131-135.

Shaw, J.E., Sicree, R.A., and Zimmet, P.Z. (2010). Global estimates of the prevalence of diabetes for 2010 and 2030. Diabetes Res Clin Pract 87, 4-14.

Shi, B., Sepp-Lorenzino, L., Prisco, M., Linsley, P., deAngelis, T., and Baserga, R. (2007). Micro RNA 145 targets the insulin receptor substrate- 1 and inhibits the growth of colon cancer cells. J Biol Chem 282, 32582-32590.

Stitt-Cavanagh, E., MacLeod, L., and Kennedy, C.R.J. (2009). The podocyte in diabetic kidney disease. Scientific World Journal I9, 1127-1139.

Tang, X.Q., Tang, G.L., and Özcan, S. (2008). Role of microRNAs in diabetes. Biochim Biophys Acta 1779, 697-701.

Teleman, A.A., and Cohen, S.M. (2006). Drosophila lacking
microRNA miR-278 are defective in energy homeostasis. Genes Dev 20, 417-422.

Trajkovski, M., Hausser, J., Soutschek, J., Bhat, B., Akin, A., Zavolan, M., Heim, M.H., and Stoffel, M. (2011). MicroRNAs 103 and 107 regulate insulin sensitivity. Nature 474, 649-653.

Uchida, T., Myers, M.G., Jr., and White, M.F. (2000). IRS-4 mediates protein kinase $B$ signaling during insulin stimulation without promoting antiapoptosis. Mol Cell Biol 20, 126-138.

Vikman, J., Ma, X.S., Hockerman, G.H., Rorsman, P., and Eliasson, L. (2006). Antibody inhibition of synaptosomal protein of $25 \mathrm{kDa}$ (SNAP-25) and syntaxin 1 reduces rapid exocytosis in insulin-secreting cells. J Mol Endocrinol 36, 503-515.

Wang, H.Y., Gauthier, B.R., Hagenfeldt-Johansson, K.A., lezzi, M., and Wollheim, C.B. (2002). Foxa2 (HNF3ß) controls multiple genes implicated in metabolism-secretion coupling of glucose-induced insulin release. J Biol Chem 277, 17564-17570.

Wang, Q., Wang, Y.L., Minto, A.W., Wang, J.H., Shi, Q., Li, X.M., and Quigg, R.J. (2008). MicroRNA-377 is up-regulated and can lead to increased fibronectin production in diabetic nephropathy. FASEB J 22, 4126-4135.

Wang, X.H., Qian, R.Z., Zhang, W., Chen, S.F., Jin, H.M., and Hu, R.M. (2009). MicroRNA-320 expression in myocardial microvascular endothelial cells and its relationship with insulin-like growth factor-1 in type 2 diabetic rats. Clin Exp Pharmacol Physiol 36, 181-188.

White, M.F. (2002). IRS proteins and the common path to diabetes. Am J Physiol Endocrinol Metab 283, E413-E422.

Wilcox, G. (2005). Insulin and insulin resistance. Clin Biochem Rev 26, 19-39.

Wilfred, B.R., Wang, W.X., and Nelson, P.T. (2007). Energizing miRNA research: a review of the role of miRNAs in lipid metabolism, with a prediction that miR-103/107 regulates human metabolic pathways. Mol Genet Metab 91, 209-217.

Wolfrum, C., Besser, D., Luca, E., and Stoffel, M. (2003). Insulin regulates the activity of forkhead transcription factor $\mathrm{Hnf}-3 \mathrm{\beta} /$ Foxa-2 by Akt-mediated phosphorylation and nuclear/cytosolic localization. Proc Natl Acad Sci U S A 100, 11624-11629.

Xu, P.Z, Vernooy, S.Y., Guo, M., and Hay, B.A. (2003). The Drosophila microRNA Mir-14 suppresses cell death and is required for normal fat metabolism. Curr Biol, 13, 790-795.

Yang, B.F., Lin, H.X., Xiao, J.N., Lu, Y.J., Luo, X.B., Li, B.X., Zhang, Y., Xu, C.Q., Bai, Y.L., Wang, H.Z., et al. (2007). The musclespecific microRNA miR-1 regulates cardiac arrhythmogenic potential by targeting GJA1 and KCNJ2. Nat Med 13, 486-491.

Zampetaki, A., Kiechl, S., Drozdov, I., Willeit, P., Mayr, U., Prokopi, M., Mayr, A., Weger, S., Oberhollenzer, F., Bonora, E., et al. (2010). Plasma microRNA profiling reveals loss of endothelial miR-126 and other microRNAs in type 2 diabetes. Circ Res 107, 810-817.

Zhao, E.P., Keller, M.P., Rabaglia, M.E., Oler, A.T., Stapleton, D.S., Schueler, K.L., Neto, E.C., Moon, J.Y., Wang, P., Wang, I.M., et al. (2009). Obesity and genetics regulate microRNAs in islets, liver, and adipose of diabetic mice. Mamm Genome 20, 476-485.

Zhu, H., Shyh-Chang, N., Segrè, A.V., Shinoda, G., Shah, S.P., Einhorn, W.S., Takeuchi, A., Engreitz, J.M., Hagan, J.P., Kharas, M.G., et al. (2011). The Lin28/let-7 axis regulates glucose metabolism. Cell1 47, 81-94. 